\title{
Epigallocatechin gallate inhibits the growth and promotes the apoptosis of bladder cancer cells
}

\author{
CHENCHEN FENG* , YATFAAT HO ${ }^{*}$, CHUANYU SUN, GUOWEI XIA, QIANG DING and BIN GU \\ Department of Urology, Huashan Hospital, Fudan University, Shanghai 200040, P.R. China
}

Received September 23, 2016; Accepted June 15, 2017

DOI: $10.3892 /$ etm.2017.4981

\begin{abstract}
Epigallocatechin gallate (EGCG) has been revealed to inhibit the proliferation and induce the apoptosis of several types of tumor, in addition to inhibiting DNA methyltransferase activity, leading to $\mathrm{CpG}$ demethylation. Tissue factor pathway inhibitor 2 (TFPI-2) expression is downregulated in bladder cancer. The present study revealed that this downregulation was partly due to hypermethylation of the TFPI-2 gene promoter, which was decreased by EGCG treatment. In addition, the present study demonstrated that EGCG could inhibit the viability and invasion, and induce the apoptosis, of bladder cancer T24 cells. Furthermore, western blot analysis and reverse transcription-quantitative polymerase chain reaction analyses demonstrated that EGCG could upregulate the expression of TFPI-2. These results suggest that EGCG inhibits the growth and induces the apoptosis of bladder cancer cells through restoring TFPI-2 expression. Thus, EGCG is a potential therapeutic candidate for the treatment of bladder cancer.
\end{abstract}

\section{Introduction}

Tissue factor pathway inhibitor 2 (TFPI-2) is a recently identified serine proteinase inhibitor, which inhibits a number of proteinases, including matrix metalloproteinase (MMP), trypsin, and fibrinogenase (1). MMP, the key enzyme that degenerates extracellular matrix, can be inhibited by TFPI-2, thus reducing tumor invasion and metastasis. TFPI-2 has been reported to have this effect in ovarian cancer, pancreatic cancer, prostate cancer and glioma (2-5). It has also been reported that the overexpression of TFPI-2 in U-251 glioma cells induces apoptosis (5). However, the mechanism by which TFPI-2 is downregulated in various cancers remains

Correspondence to: $\mathrm{Dr} \mathrm{Bin} \mathrm{Gu}$, Department of Urology, Huashan Hospital, Fudan University, 12 Central Urumqi Road, Shanghai 200040, P.R. China

E-mail: gubinurol@163.com

${ }^{*}$ Contributed equally

Key words: epigallocatechin gallate, tissue factor pathway inhibitor 2, bladder cancer, methylation undetermined. It has been reported that the downregulation of TFPI-2 in pancreatic cancer, glioma and hepatic cancer could result from $\mathrm{CpG}$ hypermethylation of promoters (6-8). Using a methylation inhibitor such as 5-Aza-2'-deoxycytidine (5-Aza-dC) could induce the expression of TFPI-2 in hepatocellular carcinoma cells (9).

Cancer is subject to genetic and epigenetic modifications. The methylation of $\mathrm{CpG}$ islands in tumor suppressors is currently thought to be the primary mechanism of epigenetic modifications in cancer. DNA methylation refers to the methylation of the fifth carbon on the pyridine ring of cytosine by DNA methyltransferase (DNMT) (10). Therapeutic methods of targeting $\mathrm{CpG}$ island methylation primarily focus on the inhibition of DNMT using drugs like 5-Aza-dC. A recent report demonstrated that epigallocatechin gallate (EGCG) can inhibit DNMT with minimal cytotoxicity and potent efficacy in solid tumors (11). EGCG is the main component of catechin in tea and conjugates with DNMT1 via four hydrogen bonds. However, no proof of health benefits of EGCG have been acknowledged in Europe or the US $(12,13)$. This may be due to the poor bioactivity of EGCG when taken orally. However, in experiments using purified EGCG, there has been promising results showing its antitumor activity (14).

Bladder cancer is the eighth most common cancer, the ninth most common cause of cancer-associated mortality and was once the most commonly diagnosed urological cancer in China prior to the era of prostate-specific antigen screening (15). However, bladder cancer remains difficult to treat. The resection of a bladder tumors that do not invade the muscle is followed by a $50 \%$ recurrence rate and $~ 50 \%$ of muscle-invading bladder tumors metastasize (14). Novel treatments based on the underlying molecular mechanisms of bladder cancer pathogenesis are urgently required. The present study aimed to determine whether TFPI-2 is hypermethylated in bladder cancer and whether the DNMT inhibitor EGCG could inhibit the progression of bladder cancer.

\section{Materials and methods}

Methylation-specific polymerase chain reaction (PCR) analysis. A total of 24 fresh tissue samples from patients diagnosed with bladder cancer were included in the present study. Normal and cancerous bladder tissue samples were obtained via transurethral resections or radical cystoprostatectomies, which were performed at Huashan Hospital (Shanghai, China). All 
patients provided written informed consent and the Ethics Committee of Huashan Hospital judged the present study to be exempt from ethical approval. Probes were constructed using PyroMark Assay Design software (version 2.0; Qiagen, Inc., Valencia, CA, USA) as follows: TFPI-2 forward, 5'-TGGTTTT TTAAAGTGTTGGGATTA-3' and reverse, 5'-ATATAACCA CCAATAAAAAATTAAAACATT-3' with 5' biotinylation; and TFPI-2 probe, 5'-AGTGTTGGGATTATAGG-3' without 5 ' biotinylation. Genomic DNA was extracted using the Qiagen DNeasy tissue kit (Qiagen GmbH; Hilden, Germany) according to the manufacturer's instructions and was subsequently dissolved using sodium bisulfite mixed with $800 \mu 1$ of RNase-free water. The mixture was placed at room temperature $\left(15-25^{\circ} \mathrm{C}\right)$ and was then subject to PCR conversion $\left(95^{\circ} \mathrm{C}\right.$ for $5 \mathrm{~min}, 60^{\circ} \mathrm{C}$ for $25 \mathrm{~min}, 95^{\circ} \mathrm{C}$ for $5 \mathrm{~min}, 60^{\circ} \mathrm{C}$ for $85 \mathrm{~min}$, $95^{\circ} \mathrm{C}$ for $5 \mathrm{~min}, 60^{\circ} \mathrm{C}$ for $175 \mathrm{~min}$ and $20^{\circ} \mathrm{C}$ for holding). Freshly prepared Buffer BL was added and samples were transported to EpiTect spin columns. Following centrifugation at $16,000 \mathrm{x} \mathrm{g}$ for $1 \mathrm{~min}$ at room temperature, $500 \mu \mathrm{l}$ of Buffer $\mathrm{BW}$ was added to the columns, which were subsequently treated with Buffer BD and left incubated at $15-25^{\circ} \mathrm{C}$ for $15 \mathrm{~min}$. Following further centrifugation at $16,000 \mathrm{x} \mathrm{g}$ for $1 \mathrm{~min}$ at room temperature, columns were treated with Buffer BW. When all remnant liquid was removed via several centrifuges, columns were incubated at $56^{\circ} \mathrm{C}$ for $5 \mathrm{~min}$. Purification was finalized with Buffer EB treatment for the collection of purified DNA. Methylation PCR was conducted using the $50 \mu \mathrm{l}$ system. Reactions were run at $95^{\circ} \mathrm{C}$ for $3 \mathrm{~min} ; 94^{\circ} \mathrm{C}$ for $30 \mathrm{sec}, 54^{\circ} \mathrm{C}$ for $30 \mathrm{sec}$, and $72^{\circ} \mathrm{C}$ for $1 \mathrm{~min}$ for 40 cycles; followed by $72^{\circ} \mathrm{C}$ for $7 \mathrm{~min}$. Pyrosequencing was performed by adding conjugated beads into PCR tubes. The beads were aspired using a vacuum pump and were immersed into $70 \%$ ethanol, $0.2 \mathrm{M} \mathrm{NaOH}$ and rinsing buffer for $5 \mathrm{sec}$ each. Beads and PCR products were subsequently treated with $40 \mu \mathrm{l}$ of annealing buffer and subjected to $85^{\circ} \mathrm{C}$ for $2 \mathrm{~min}$ prior to cooling down to room temperature. Quantity of substrate, enzyme, and dNTP (Qiagen, Inc.) added was obtained using Pyrose quenching software (PyroMark Q96 ID; Qiagen, Inc.). Pyro Q-CpG software (version 1.0) was used for automatic analysis of the methylation status of TFPI-2.

Reverse transcription-quantitative PCR (RT-qPCR). For RT-qPCR, total RNA was extracted from T24 cells or normal bladder tissue with TRIzol (Invitrogen; Thermo Fisher Scientific, Inc., Waltham, MA, USA). Tissue was ground and treated with $1 \mathrm{ml}$ of TRIzol reagent. Samples were subsequently treated with chloroform and subject to centrifugation at $16,000 \mathrm{x} \mathrm{g}$ for $15 \mathrm{~min}$ at $4^{\circ} \mathrm{C}$. Supernatants were extracted and treated with isopropanol. Following centrifugation at $16,000 \times \mathrm{g}$ for $10 \mathrm{~min}$ at $4^{\circ} \mathrm{C}$, supernatant was dispersed and RNA was dissolved in ethanol. Following centrifugation, products was maintained in diethyl pyrocarbonate water. The RNA concentration was determined using a spectrophotometer. Retro-transcription was conducted in the system with $5 \mathrm{X}$ All-In-One RT MasterMix, extracted RNA, and water. Reactions were run at $37^{\circ} \mathrm{C}$ for $15 \mathrm{~min}$ and $85^{\circ} \mathrm{C}$ for $5 \mathrm{sec}$ and RNA was maintained at $-20^{\circ} \mathrm{C}$. The primers used for qPCR were as follows: TFPI-2 forward, 5'-CTTGCGACGATGCTT GCTG-3' and reverse, 5'-ACACCCACCGGAAAAGAA TTT-3'; and GAPDH forward, 5'-ATGGGGAAGGTGAAGG
TCG-3' and reverse, 5'-GGGGTCATTGATGGCAACA ATA-3'. PCR reactions were run in the system containing SYBR-Green, primers, RoxDye (II), RT products, and water. Cycling condition used were as follows: $95^{\circ} \mathrm{C}$ for $30 \mathrm{sec} ; 95^{\circ} \mathrm{C}$ for $3 \mathrm{sec}$ and $60^{\circ} \mathrm{C}$ for $30 \mathrm{sec}$ for a total of 40 cycles. For each sample, the average threshold cycle value was normalized to GAPDH and the relative expression was quantified according to the $2^{-\Delta \Delta \mathrm{Cq}}$ method (16).

Western blotting. An established protocol was used for western blotting (17-20). Total protein was extracted from T24 cells or normal bladder tissue. Briefly, to prepare cellular protein, plates were placed on ice and treated with pre-chilled proteinase inhibitor consisting of phenylmethylsulfonyl fluoride and phosphatase and were subsequently treated with protein extraction kit (Sangon Biotech Co., Ltd., Shanghai, China). Cells were scraped and debris were filtered using centrifuge. Tissue chunks were sliced and homogenated using the same agents. Samples were treated with lysate and proteins were prepared similarly to cells. Protein concentration was determined via the bicinchoninic acid (BCA) assay (Sangon Biotech Co., Ltd.). A total of $50 \mu \mathrm{g}$ protein were separated by SDS-PAGE on a $10 \%$ gel and subsequently transferred to a polyvinylidene difluoride membrane at a constant voltage. Following blocking using 5\% bovine serum albumin (Gibco; Thermo Fisher Scientific, Inc.) at room temperature overnight, TFPI-2 primary antibodies (cat. no. YT5159; ImmunoWay Biotechnology Company, Suzhou, Shina) were diluted to 1:5,000 with Tris-buffered saline/Tween-20 and incubated with the membranes for $90 \mathrm{~min}$ at room temperature. Following washing using tris buffered saline with Tween-20 three times, the membrane was incubated with horseradish peroxidase-labeled goat anti-rabbit IgG secondary antibody diluted at 1:1,000 (cat. no. 111-035-003; Jackson ImmunoResearch Laboratories, Inc., West Grove, PA, USA). Protein bands were then detected using chemiluminescence and autoradiography (ChemiDoc XRS; Bio-Rad Laboratories, Inc., Hercules, CA, USA). Densitometry was determined using the Quantity One software version 4.6.2 (Bio-Rad Laboratories, Inc., Hercules, CA, USA).

Cell culture. Human T24 bladder urothelial cancer cells were purchased from the Cell Bank of the Chinese Academy of Sciences (Shanghai, China). T24 cells were cultured in RPMI-1640 (Gibco; Thermo Fisher Scientific, Inc.) supplemented with $10 \%$ fetal bovine serum (Gibco; Thermo Fisher Scientific, Inc.) at $37^{\circ} \mathrm{C}$ in an atmosphere containing $5 \% \mathrm{CO}_{2}$. Cells were subsequently treated with different concentrations of EGCG (10 and $20 \mu \mathrm{M}$ ) or PBS buffer (control) for 6 days.

MTT assay. Briefly, 500 cells/well were seeded into 96-well plates. Cells were incubated at $37^{\circ} \mathrm{C}$ and treated with MTT and dimethyl sulfoxide for $4 \mathrm{~h}$ and $10 \mathrm{~min}$ at $37^{\circ} \mathrm{C}$, respectively. Treated (EGCG vs. PBS as control) cells were analyzed on a plate reader and quantified by measuring the absorbance at $490 \mathrm{~nm}$.

Apoptosis assay. For flow cytometry, the Annexin V-fluorescein isothiocyanate (FITC) and propidium iodide (PI) (BD) method was employed using an Annexin V/FITC kit (BD Biosciences, 
A

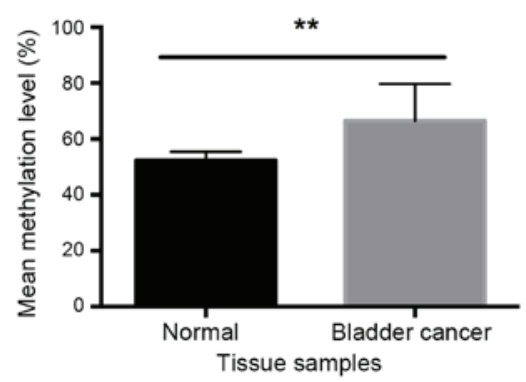

B

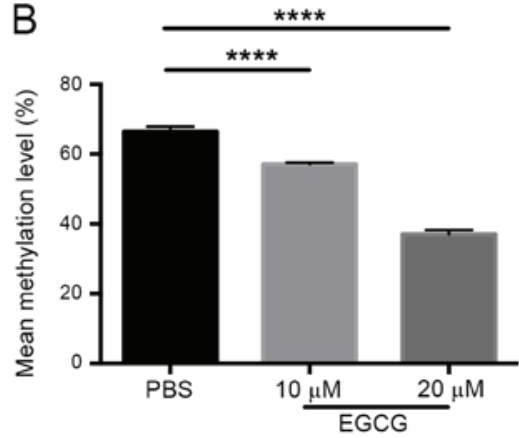

Figure 1. Methylation of the TFPI-2 gene in bladder cancer is decreased by EGCG. Methylation-specific polymerase chain reaction analysis revealed (A) a significantly higher methylation level of TFPI-2 in bladder cancer compared with normal bladder tissue, and (B) significantly decreased methylation of TFPI-2 in T24 bladder cancer cells treated with EGCG. ${ }^{* *} \mathrm{P}<0.01,{ }^{* * * *} \mathrm{P}<0.0001$. TFPI-2, tissue factor pathway inhibitor 2; EGCG, epigallocatechin gallate.
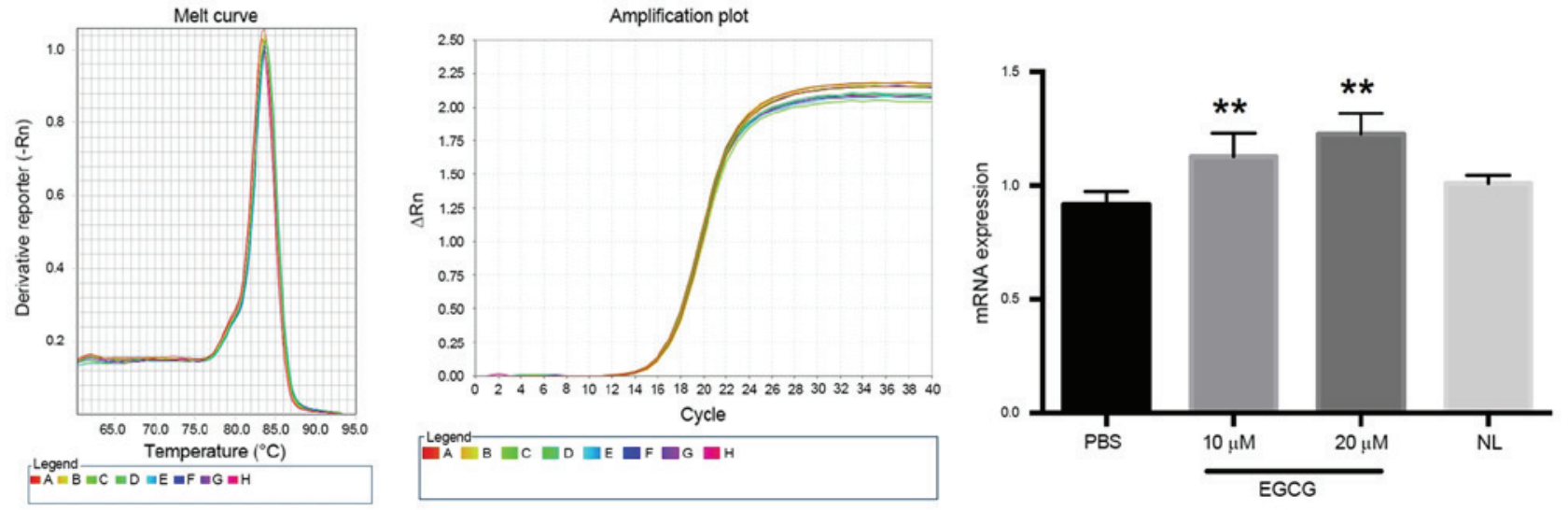

Figure 2. EGCG restores the expression of TFPI-2 mRNA in bladder cancer cells. Reverse transcription-quantitative polymerase chain reaction analysis of TFPI-2 revealed increased TFPI- 2 mRNA expression in T24 bladder cancer cells treated with different doses of EGCG compared with the PBS-treated control. ${ }^{* *} \mathrm{P}<0.01$ vs. the PBS control group. TFPI-2, tissue factor pathway inhibitor 2; EGCG, epigallocatechin gallate; NS, no significance; NL, healthy adjacent bladder tissue.

San Jose, CA, USA) according to the manufacturer's instructions. T24 bladder cancer cells were harvested and HEPES binding buffer containing Annexin V-FITC and PI was applied for $15 \mathrm{~min}$ at room temperature. Samples were analyzed using a FACSCanto $^{\mathrm{TM}}$ flow cytometer (BD Biosciences) to determine the percentage of early apoptotic cells (Annexin $\mathrm{V}^{+} / \mathrm{PI}^{-}$).

Cell invasion assay. A Transwell assay was used to investigate the invasive abilities of the T24 bladder cancer cells. Briefly, Transwell inserts were coated with Matrigel (1:2 dilution; BD Biosciences). Prior to placing the inserts into the chambers, the chambers were filled with complete media. Approximately $1 \times 10^{6}$ cells $/ \mathrm{ml}$ were seeded in $300 \mu \mathrm{l}$ of serum-free RPMI-1640 medium with the addition of EGCG in the inserts, which were subsequently placed into the chambers. After $72 \mathrm{~h}$ of incubation, the inserts were stained with crystal violet at room temperature for $30 \mathrm{~min}$ and the number of invasive cells was counted using a light microscope at a magnification of x100 (Nikon 80i Eclipse; Sendai, Japan).

Statistical analysis. Data are presented as the mean \pm standard deviation. All experiments were performed in triplicate and were two-tailed. The unpaired t-test was used to determine the statistical significance of differences between two groups. For comparisons between more than two groups, one-way analysis of variance with a post hoc Geisser-Greenhouse correction was used. $\mathrm{P}<0.05$ was considered to indicate a statistically significant difference. Statistical analyses were performed using SPSS v17 software (SPSS, Inc., Chicago, IL, USA).

\section{Results}

Methylation of the TFPI-2 gene in bladder cancer is decreased by EGCG. Our group has previously demonstrated decreased expression of TFPI-2 in renal cell carcinoma and bladder cancer $(17,21)$. The present study investigated whether this decrease in expression was a result of DNA methylation. A total of 24 bladder cancer samples were analyzed, which revealed a significantly higher methylation level in the TFPI-2 gene compared with healthy adjacent bladder tissue $(\mathrm{P}<0.01$; Fig. 1A). DNA methylation levels of the TFPI-2 gene in the bladder cancer cells treated EGCG were significantly decreased compared with the control cells $(\mathrm{P}<0.0001$; Fig. 1B).

EGCG restores the expression of TFPI-2 in bladder cancer cells. Our group has previously reported that EGCG restores TFPI-2 expression levels in renal cell carcinoma (17). The present study investigated the effect of EGCG on the expression of TFPI-2 in bladder cancer (Fig. 2). EGCG significantly increased TFPI-2 mRNA expression compared with the control 


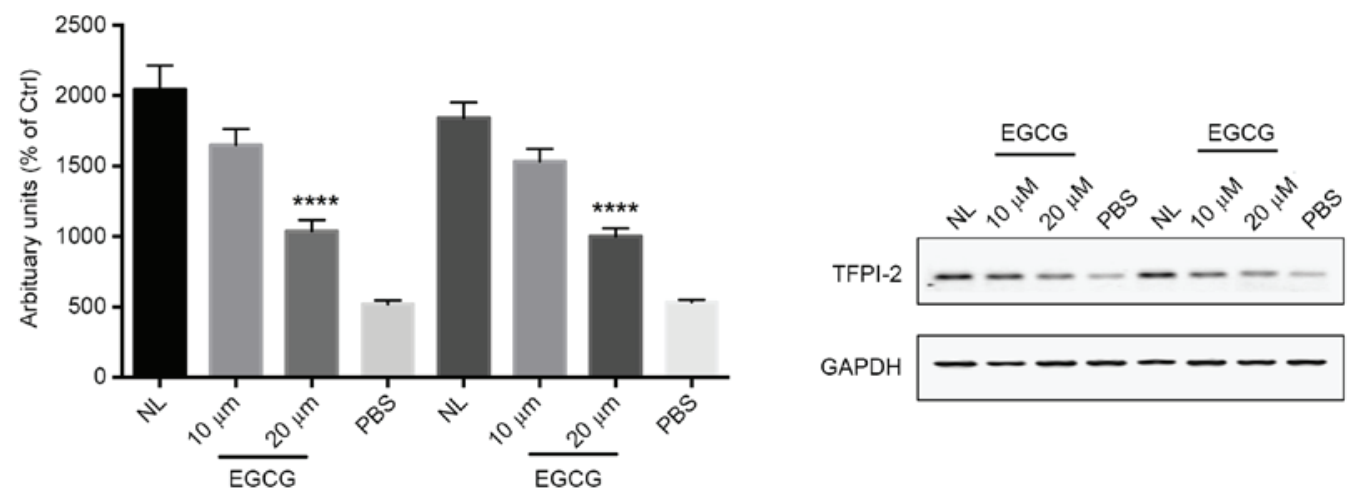

Figure 3. EGCG restores the expression of TFPI-2 protein in bladder cancer cells. Western blotting for TFPI-2 revealed an increased TFPI-2 protein level in T24 bladder cancer cells treated with different doses of EGCG. ${ }^{* * * *} \mathrm{P}<0.0001$ vs. the PBS control group. TFPI-2, tissue factor pathway inhibitor 2; EGCG, epigallocatechin gallate; NL, healthy adjacent bladder tissue.
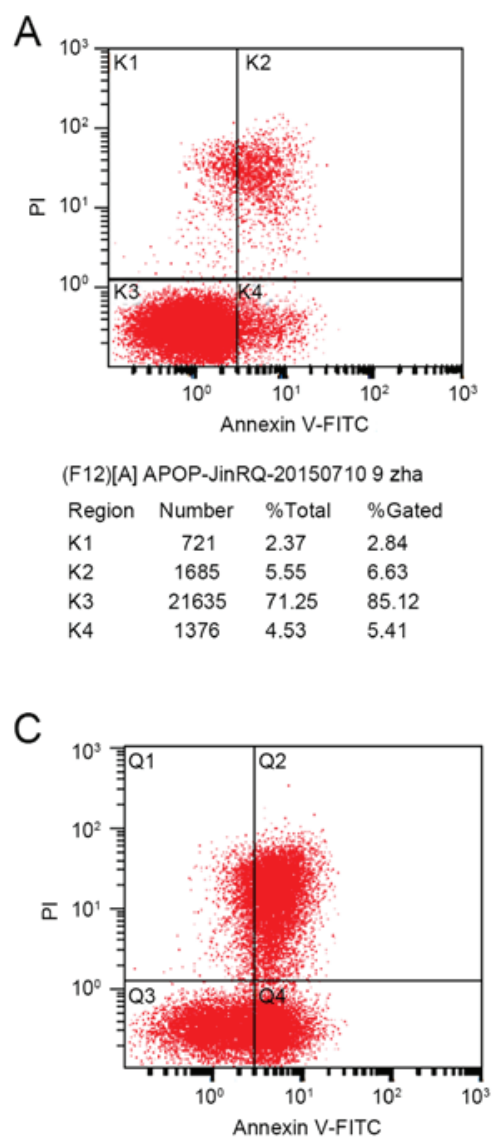

(F18)[A] APOP-JinRQ-20150710 15 zhang 00

$\begin{array}{lcll}\text { Region } & \text { Number } & \text { \% Total } & \text { \%Gated } \\ \text { Q1 } & 1897 & 5.92 & 6.43 \\ \text { Q2 } & 11736 & 36.61 & 39.77 \\ \text { Q3 } & 8149 & 25.42 & 27.61 \\ \text { Q4 } & 7728 & 24.11 & 26.19\end{array}$

B

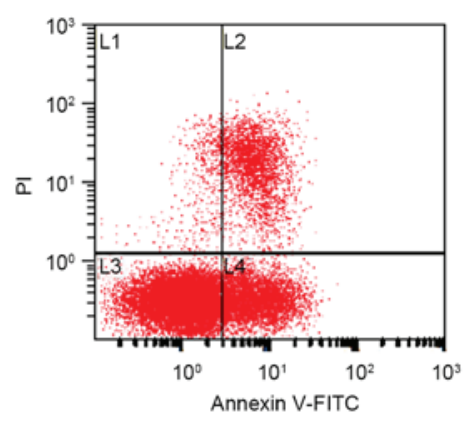

(F13)[A] APOP-JinRQ-20150710 10 zha

Region Number \%Total \%Gated

$\begin{array}{llll}\text { L1 } & 518 & 1.70 & 1.97\end{array}$

$\begin{array}{llll}\text { L2 } & 3163 & 10.36 & 12.03\end{array}$

L3 $\quad 17623 \quad 57.71 \quad 67.03$

$\begin{array}{llll}\text { L4 } & 4988 & 16.34 & 18.97\end{array}$

$\mathrm{D}$

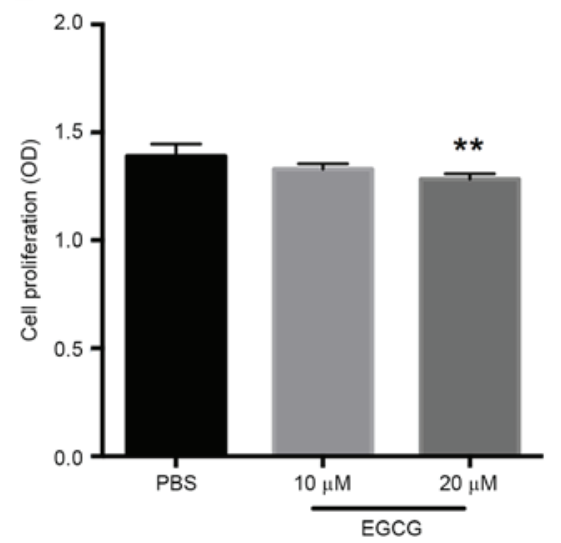

Figure 4. EGCG increases the apoptosis and decreases the viability of bladder cancer cells. The results of the apoptosis assay of the (A) PBS-treated control, (B) $10 \mu \mathrm{m}$ EGCG and (C) $20 \mu \mathrm{m}$ EGCG groups demonstrated increased apoptosis in the EGCG treated cells. (D) The cell viability assay revealed that $20 \mu \mathrm{m}$ EGCG significantly inhibited bladder cancer cell growth. ${ }^{* *} \mathrm{P}<0.01$ vs. the PBS control group. EGCG, epigallocatechin gallate; NS, no significance; FITC, fluorescein isothiocyanate; PI, propidium iodide.

group $(\mathrm{P}<0.01)$ in a dose-dependent manner. Notably, normal bladder tissue exhibited a similar level of TFPI-2 expression compared with T24 bladder cancer cells. The protein level of TFPI-2 in bladder cancer cells treated with different doses of EGCG was then investigated (Fig. 3), which revealed that the protein level of TFPI-2 was significantly increased in response to $20 \mu \mathrm{m}$ EGCG compared with the control group $(\mathrm{P}<0.0001)$. By contrast, the protein level of TFPI- 2 in T24 bladder cancer cells was marked lower compared with that in adjacent healthy bladder tissue. 

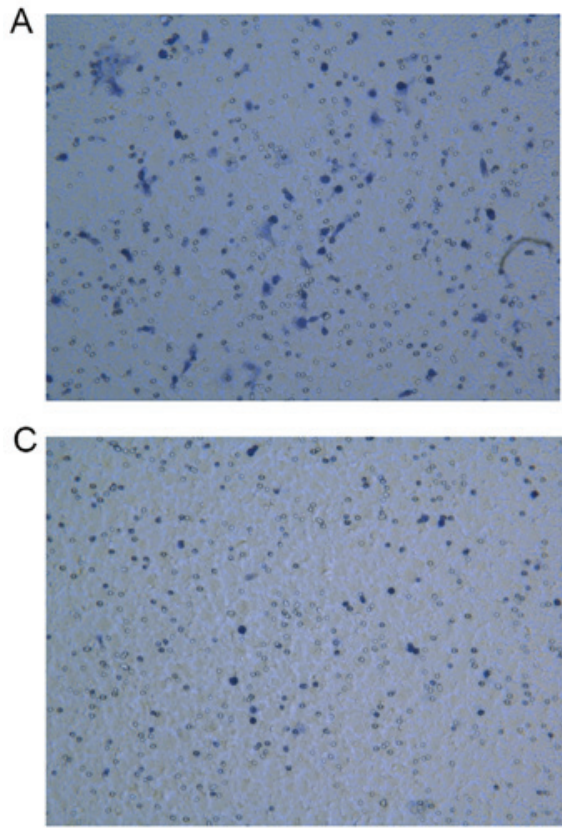
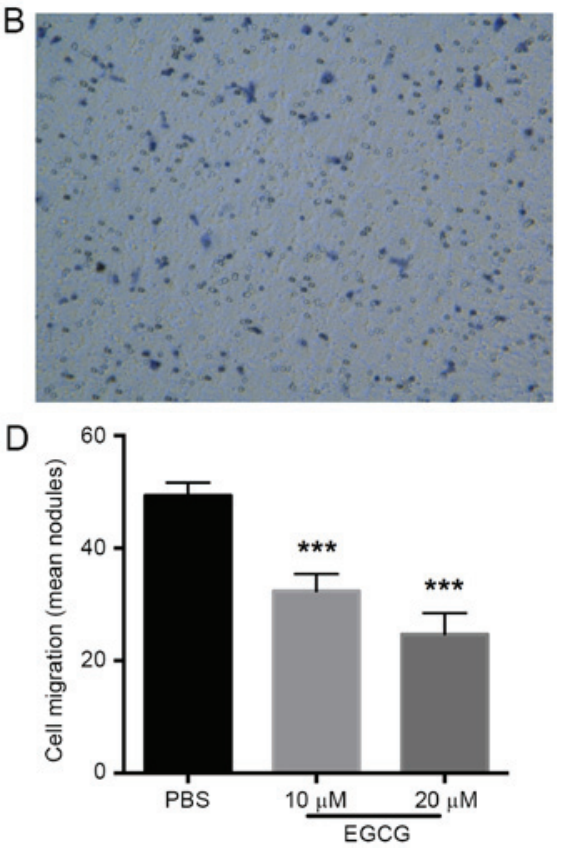

Figure 5. EGCG inhibits the invasion of bladder cancer cells. The results of the Transwell invasion assay at a magnification of x100 of the (A) PBS-treated control, (B) $10 \mu \mathrm{m}$ EGCG and (C) $20 \mu \mathrm{m}$ EGCG groups wells. (D) Quantification of the Transwell invasion assay revealed that 10 and $20 \mu \mathrm{m}$ EGCG treatment significantly inhibited bladder cancer cell invasion. ${ }^{* * *} \mathrm{P}<0.001$ vs. the PBS control group. EGCG, epigallocatechin gallate.

EGCG increases the apoptosis, and inhibits the viability and invasion of bladder cancer cells. Given the restoration of TFPI-2 expression in the T24 bladder cancer cells following EGCG treatment, the effect of EGCG was further investigated in vitro. This revealed that the apoptosis of bladder cancer cells was notably increased by $20 \mu \mathrm{m}$ EGCG (Fig. 4A-C). In addition, $20 \mu \mathrm{m}$ EGCG inhibited bladder cancer cell viability $(\mathrm{P}<0.01$ vs. the control group; Fig. 4D). However, $10 \mu \mathrm{m}$ EGCG did not exhibit any significant inhibitory effect on T24 cell viability (Fig. 4D). The effect of EGCG on the invasive ability of the bladder cancer cells was then investigated, which demonstrated that EGCG significantly inhibited invasion compared with the control group $(\mathrm{P}<0.01$; Fig. 5).

\section{Discussion}

Although substantial progress has been made in the treatment of bladder cancer, the outcome of patients with invasive bladder cancer has not substantially improved in the last 20 years. Novel treatments that target specific tumor-associated targets, including TFPI-2, could minimize adverse advents and enhance treatment efficacy. However, the role of TFPI-2 in bladder cancer remains unclear. Our group has previous identified that TFPI-2 is downregulated in bladder cancer (21). In addition, the present study identified that the TFPI-2 gene was hypermethlyated in bladder cancer. It was thus hypothesized that inhibition of TFPI-2 methylation via the administration of EGCG could restore TFPI-2 expression and inhibit tumor growth. Several previous studies have investigated the effect of tea extracts, including ECGC, in cancer therapy $(22,23)$. Hypermethylated tumor suppressors are a common characteristic of cancer, and bioactive flavonoids that are natural extracts from fruits, vegetables and other plants have been proposed to decrease hypermethylation (24). EGCG, an antioxidant polyphenol flavonoid isolated from green tea, has been identified to serve a chemopreventive role by certain studies (25). The effect of EGCG in atherosclerosis and neurodegenerative diseases, in addition to cancer, is being investigated. Specifically, EGCG has been suggested to function via the following mechanisms in cancer: i) Inducing apoptosis (26-28); ii) inhibiting epidermal growth factor receptor-mediated signaling pathways $(29,30)$; iii) inhibiting signaling between vascular endothelial growth factor and MMPs, thus compromising angiogenesis $(31,32)$; iv) inhibiting telomerase and DNMT (33-36); and v) reducing oxidative stress levels (35).

To the best of our knowledge, our group is the first to demonstrate that TFPI-2 could be one of the genes for which DNA methylation is inhibited by EGCG. A previous study by our group investigating renal cell carcinoma demonstrated a similar result concerning TFPI-2 hypermethylation (17). The present study demonstrated that methylation of the TFPI-2 gene is prevalent in bladder cancer. Previous investigations of prostate cancer and TFPI-2 have revealed that the methylation of TFPI-2 is a common feature of urological malignancies (4). In addition, it has previously been shown that TFPI-2 expression is inversely associated with progression of malignancies in general (1-11). Notably, coagulation abnormalities are a common characteristic of cancer. Tissue factor (TF) promotes clotting and thus promotes the progression of malignancies (37). TFPI-2 inhibits TF and thus cancer growth. Aberrant methylation of TFPI-2 promoter CpG islands in human cancer and cancer cell lines is widely accepted to be responsible for the downregulation of TFPI-2 expression during cancer progression (4). Additionally, an aberrantly spliced variant of TFPI-2 mRNA that leads to an untranslated form of TFPI-2 is also responsible for loss of TFPI-2 function (38).

In conclusion, the results of the present study indicate that ECGC restores TFPI-2 expression in bladder cancer, thus 
inhibiting invasion and viability, and increasing apoptosis. Therefore, ECGC is novel therapeutic candidate for the treatment of patients with bladder cancer and requires further study.

\section{Acknowledgements}

The present study was supported by the Shanghai Municipal Health Bureau (grant no. 20114260).

\section{References}

1. Zhai LL, Cai CY, Wu Y and Tang ZG: Correlation and prognostic significance of MMP-2 and TFPI-2 differential expression in pancreatic carcinoma. Int J Clin Exp Pathol 8: 682-691, 2015.

2. Arakawa N, Miyagi E, Nomura A, Morita E, Ino Y, Ohtake N, Miyagi Y, Hirahara F and Hirano H: Secretome-based identification of TFPI2, a novel serum biomarker for detection of ovarian clear cell adenocarcinoma. J Proteome Res 12: 4340-4350, 2013.

3. Tang Z, Geng G, Huang Q, Xu G, Hu H, Chen J and Li J: Prognostic significance of tissue factor pathway inhibitor-2 in pancreatic carcinoma and its effect on tumor invasion and metastasis. Med Oncol 27: 867-875, 2010.

4. Ribarska T, Ingenwerth M, Goering W, Engers R and Schulz WA: Epigenetic inactivation of the placentally imprinted tumor suppressor gene TFPI2 in prostate carcinoma. Cancer Genomics Proteomics 7: 51-60, 2010.

5. George J, Gondi CS, Dinh DH, Gujrati M and Rao JS: Restoration of tissue factor pathway inhibitor-2 in a human glioblastoma cell line triggers caspase-mediated pathway and apoptosis. Clin Cancer Res 13: 3507-3517, 2007.

6. Sun FK, Sun Q, Fan YC, Gao S, Zhao J, Li F, Jia YB, Liu C, Wang LY, Li XY, et al: Methylation of tissue factor pathway inhibitor 2 as a prognostic biomarker for hepatocellular carcinoma after hepatectomy. J Gastroenterol Hepatol 31: 484-492, 2016.

7. Parsi MA, Li A, Li CP and Goggins M: DNA methylation alterations in endoscopic retrograde cholangiopancreatography brush samples of patients with suspected pancreaticobiliary disease. Clin Gastroenterol Hepatol 6: 1270-1278, 2008.

8. Konduri SD, Srivenugopal KS, Yanamandra N, Dinh DH, Olivero WC, Gujrati M, Foster DC, Kisiel W, Ali-Osman F, Kondraganti S, et al: Promoter methylation and silencing of the tissue factor pathway inhibitor-2 (TFPI-2), a gene encoding an inhibitor of matrix metalloproteinases in human glioma cells Oncogene 22: 4509-4516, 2003.

9. Wong CM, Ng YL, Lee JM, Wong CC, Cheung OF, Chan CY, Tung EK, Ching YP and Ng IO: Tissue factor pathway inhibitor-2 as a frequently silenced tumor suppressor gene in hepatocellular carcinoma. Hepatology 45: 1129-1138, 2007.

10. Supic G, Kozomara R, Zeljic K, Jovic N and Magic Z: Prognostic value of the DNMTs mRNA expression and genetic polymorphisms on the clinical outcome in oral cancer patients. Clin Oral Investig 21: 173-182, 2017.

11. Zhang Y, Wang X, Han L, Zhou Y and Sun S: Green tea polyphenol EGCG reverse cisplatin resistance of A549/DDP cell line through candidate genes demethylation. Biomed Pharmacother 69: 285-290, 2015.

12. Mereles D and Hunstein W: Epigallocatechin-3-gallate (EGCG) for clinical trials: More pitfalls than promises? Int J Mol Sci 12 5592-5603, 2011.

13. Fürst $\mathrm{R}$ and Zündorf I: Plant-derived anti-inflammatory compounds: Hopes and disappointments regarding the translation of preclinical knowledge into clinical progress. Mediators Inflamm 2014: 146832, 2014.

14. Fassina G, Venè R, Morini M, Minghelli S, Benelli R, Noonan DM and Albini A: Mechanisms of inhibition of tumor angiogenesis and vascular tumor growth by epigallocatechin-3-gallate. Clin Cancer Res 10: 4865-4873, 2004.

15. Masaoka H, Matsuo K, Ito H, Wakai K, Nagata C, Nakayama T, Sadakane A, Tanaka K, Tamakoshi A, Sugawara Y, et al: Cigarette smoking and bladder cancer risk: An evaluation based on a systematic review of epidemiologic evidence in the Japanese population. Jpn J Clin Oncol 46: 273-283, 2016.

16. Livak KJ and Schmittgen TD: Analysis of relative gene expression data using real-tie quantitative PCR and the 2(-Delta Delta C(T)) method. Methods 25: 402-408, 2001.
17. Gu B, Ding Q, Xia G and Fang Z: EGCG inhibits growth and induces apoptosis in renal cell carcinoma through TFPI-2 overexpression. Oncol Rep 21: 635-640, 2009.

18. Feng CC, Wang PH, Ding Q, Guan M, Zhang YF, Jiang HW, Wen $\mathrm{H}$ and Wu Z: Expression of pigment epithelium-derived factor and tumor necrosis factor- $\alpha$ is correlated in bladder tumor and is related to tumor angiogenesis. Urol Oncol 31: 241-246, 2013.

19. Feng C, Sun Y, Ding G, Wu Z, Jiang H, Wang L, Ding Q and Wen H: PI3K $\beta$ inhibitor TGX221 selectively inhibits renal cell carcinoma cells with both VHL and SETD2 mutations and links multiple pathways. Sci Rep 5: 9465, 2015.

20. Feng C, Ding G, Jiang H, Ding Q and Wen H: Loss of MLH1 confers resistance to PI3K $\beta$ inhibitors in renal clear cell carcinoma with SETD2 mutation. Tumour Biol 36: 3457-3464, 2015.

21. Feng C, Ho Y, Sun C, Xia G, Ding Q and Gu B: TFPI-2 expression is decreased in bladder cancer and is related to apoptosis. J BUON 21: 1518-1523, 2016.

22. Granja A, Pinheiro M and Reis S: Epigallocatechin gallate nanodelivery systems for cancer therapy. Nutrients 8: pii:E307, 2016.

23. Esmaeili MA: Combination of siRNA-directed gene silencing with epigallocatechin-3-gallate (EGCG) reverses drug resistance in human breast cancer cells. J Chem Biol 9: 41-52, 2015.

24. Mukherjee N, Kumar AP and Ghosh R: DNA methylation and flavonoids in genitourinary cancers. Curr Pharmacol Rep 1: 112-120, 2015.

25. Gan RY, Li HB, Sui ZQ and Corke H: Absorption, metabolism, anti-cancer effect and molecular targets of epigallocatechin gallate (EGCG): An updated review. Crit Rev Food Sci Nutr 19: $1-18,2016$.

26. Borska S, Gebarowska E, Wysocka T, Drag-Zalesinska M and Zabel M: Induction of apoptosis by EGCG in selected tumour cell lines in vitro. Folia Histochem Cytobiol 41: 229-232, 2003.

27. Lambert JD and Yang CS: Mechanisms of cancer prevention by tea constituents. J Nutr 133: 3262S-3267S, 2003.

28. Gupta S, Hastak K, Afaq F, Ahmad N and Mukhtar H: Essential role of caspases in epigallocatechin-3-gallate-mediated inhibition of nuclear factor kappa B and induction of apoptosis. Oncogene 23: 2507-2522, 2004.

29. Masuda M, Suzui M, Lim JT and Weinstein IB: Epigallocatechin-3-gallate inhibits activation of HER-2/neu and downstream signaling pathways in human head and neck and breast carcinoma cells. Clin Cancer Res 9: 3486-3491, 2003.

30. Sah JF, Balasubramanian S, Eckert RL and Rorke EA: Epigallocatechin-3-gallate inhibits epidermal growth factor receptor signaling pathway. Evidence for direct inhibition of ERK1/2 and AKT kinases. J Biol Chem 279: 12755-12762, 2004.

31. Tang FY, Nguyen $\mathrm{N}$ and Meydani M: Green tea catechins inhibit VEGF-induced angiogenesis in vitro through suppression of VE-cadherin phosphorylation and inactivation of Akt molecule. Int J Cancer 106: 871-878, 2003.

32. Tosetti F, Ferrari N, De Flora S and Albini A: Angioprevention': Angiogenesis is a common and key target for cancer chemopreventive agents. FASEB J 16: 2-146, 2002.

33. Yokoyama M, Noguchi M, Nakao Y, Pater A and Iwasaka T: The tea polyphenol, (-)-epigallocatechin gallate effects on growth, apoptosis and telomerase activity in cervical cell lines. Gynecol Oncol 92: 197-204, 2004.

34. Didiano D, Shalaby T, Lang D and Grotzer MA: Telomere maintenance in childhood primitive neuroectodermal brain tumors. Neuro Oncol 6: 1-8, 2004.

35. Mittal A, Pate MS, Wylie RC, Tollefsbol TO and Katiyar SK: EGCG down-regulates telomerase in human breast carcinoma MCF-7 cells, leading to suppression of cell viability and induction of apoptosis. Int J Oncol 24: 703-710, 2004.

36. Lee SR, Im KJ, Suh SI and Jung JG: Protective effect of green tea polyphenol (-)-epigallocatechin gallate and other antioxidants on lipid peroxidation in gerbil brain homogenates. Phytother Res 17: 206-209, 2003

37. Adesanya MA, Maraveyas A and Madden LA: Cancer microvesicles induce tissue factor-related procoagulant activity in endothelial cells in vitro. Blood Coagul Fibrinolysis 28: 365-372, 2017.

38. Sierko E, Wojtukiewicz MZ and Kisiel W: The role of tissue factor pathway inhibitor-2 in cancer biology. Semin Thromb Hemost 33: 653-659, 2007. 